\title{
АЙВАЗЯН НУНЭ
}

Преподаватель факультета русской филологии кафедры русского языка для гуманитарных факультетов ЕГУ

\section{К НЕКОТОРЫМ ВОПРОСАМ ТЕОРЕТИЧЕСКИХ ОСНОВ ПРЕПОДАВАНИЯ РКИ}

Преподавание русского как иностранного в РА на сегодняшний день является одной из самых важных и актуальных проблем. В статье анализируются основные подходы и современные методы преподавания РКИ на начальном этапе, а также презентуется учебник русского языка для начинающих (элементарный уровень), созданный в соавторстве с русистами ЕГУ и прошедший апробацию на подготовительном факультете для иностранных граждан ЕГУ. В учебнике методика РКИ адаптирована как для студентов-армян, не владеющих русским языком, так и для иностранных граждан, приезжающих в РА.

Ключевые слова: методика преподавания РКИ, умения, навыки, элементарный уровень, особенности, закономерности, модели-предложения, коммуникативный метод, речевые образцы, учебники по РКИ.

В наше время изучение иностранных языков очень популярно и актуально. И зачастую многие, начинающие обучение, пренебрегают знаниями правил по грамматике и лексике, чаще предпочитая смело, свободно и легко общаться на иностранном языке, просто и не задумываясь строить фразы. На закрепление, «шлифование» и улучшение этих навыков и направлена существующая методика РКИ.

Она была разработана в 50-60-е годы XX века в МГУ для решения главной задачи - эффективно и быстро обучить студентов русскому языку, чтобы в дальнейшем они легко могли освоить предметы по выбранной специальности. Успех был очевиден: всего за 700 аудиторных часов никогда не слышавшие до этого русской речи студенты научились не только говорить по-русски, но и понимать лектора, слушать лекции, писать рефераты и дипломные работы, даже защищать диссертации. По этой методике работали многие русисты ведущих вузов бывшего Советского Союза, в том числе и преподаватели подготовительного факультета для иностранных граждан (ныне - Международный образовательный центр) ЕГУ.

«Овладеть русским» - значит уметь: понимать и различать смысл речи (реагировать адекватно), грамотно и красиво говорить (с учетом всех особенностей русской интонации и фонетики), безошибочно писать, а также быстро и внятно читать, улавливая суть прочитанного.

Остановимся на некоторых особенностях методики преподавания РКИ.

1) Изучение и освоение русского языка осуществляется при помощи моделей. С свою очередь, модель - это образец, предложение, по которому с помощью подстановки аналогичных слов создаются одинаковые по структуре предложения. На моделях-предложениях отрабатывается не только грамматика, но и интонация и фонетика, поскольку они являются цельными структурами. Уже с самого первого урока, проводимого по методике РКИ, учащиеся начинают говорить без заучивания отдельных слов. Простые предложения (Это брат и сестра. Вот стол. Это тетрадь, а это книга.) запоминаются довольно легко. При последующем повторении в упражнениях заменяются слова, то есть накапливается лексика. У студента появляется 
чувство уверенности в то, что он уже в состоянии говорить по-русски, а это, в свою очередь, является прекрасным стимулом для дальнейших занятий.

2) Грамматический материал вводится последовательно и зависит от частотности употребления тех или иных грамматических форм в языке. Последовательность, по которой вводятся падежи, зависит от того, какие из падежных значений чаще встречаются в языке. Так, используя вместо существительных личные местоимения, студенты ознакамливаются с категорией рода: Вот стол, он здесь. Где тетрадь? Она тут. Окно справа? Нет, оно слева. Это не является изучением именительного падежа, а является изучением модели с субъектом, выраженным именительным падежом личного местоимения или существительного.

После этого мы подходим к выражению определительных отношений: прилагательные даются легко, поскольку уже были введены (на моделях) притяжательные местоимения (мой, моя, моё, твой и т. д.). Далее последовательно вводятся глаголы, сначала на -ать (делать, читать, отовхать, знать, работать, понимать и т. д.), затем на -еть (смотреть) и на -ить (любить, говорить).

В школах значению падежей не уделяют достаточного внимания. О них практически не упоминают при подготовке будущих учителей, ведь для носителя русского языка и так ясно, что «сказать кому?», а «попросить, спросить - кого?». Для иностранца данное изучение без понимания падежных значений невозможно.

На занятиях по методике РКИ у иностранцев нет необходимости заучивать правила по орфографии, спряжению, склонению и другим разделам филологии, составляющие теоретические знания о языке.

3) Заучивание грамматических правил не помогает студенту-иностранцу грамотно говорить или писать, и он возможно забудет правила, если не будет в дальнейшем заниматься лингвистикой. Методика даёт студенту грамматические модели (специально составленные предложения) взамен зазубриваемым правилам. В них представлены эти правила и при помощи неоднократного повторения легко запоминаются на всю жизнь. Это и является третьей особенностью преподавания методики РКИ - обучение коммуникации (коммуникативный принцип обучения).

4) С первых уроков студент учится говорить, писать и читать одновременно (не поэтапно). Это помогает ускорить процесс освоения языка и создает у него правильное представление об особенностях и различиях русского произношения и правописания, приучает его грамотно соотносить написанное и звучащее письмо. Для русскоязычного студента, хорошо знающего язык в устной форме, проблемой может стать надобность запоминать массу грамматических правил. Дело в том, что в памяти у него уже есть звуковой (фонетический) образ слова, а грамматика требует иного написания. Например, может возникнуть вопрос, почему в слове, которое он произносит как “хАрАшо”, он должен писать “о”. Иностранец же воспринимает это слово в письменном (графическом) и звуковом образах, поэтому он никогда не напишет слово “хАрАшо”: вслед за прочитанным у него закрепится графический образ слова.

Интонация и фонетика не могут изучаться отдельно от предложений. Учащиеся всегда подражают педагогу, и именно поэтому преподаватель обязан следить за произношением. Он постоянно должен уделять большое внимание корректной интонации и фонетике.

5) Постепенно - по мере ввода новой грамматики - модели усложняются, наполняясь новой лексикой. Слова должны быть тщательно отобраны в соответствии с частотой их употребления. В этом заключается пятая особенность преподавания. 
Расширение словарного запаса идет за счет внимания к словообразованию. Студенты создают слова по знакомым моделям, употребляя приставки, суффиксы. Такая форма работы может стать очень привлекательной, если она поощряется преподавателем.

Как известно, для того, чтобы хорошо освоить язык, надо прежде всего овладеть как грамматикой, то есть тем, без чего невозможно грамотно построить предложение, так и лексикой, т. е. словами, чаще всего употребляющимися в языке. Этот минимум составляет 14001500 слов. Постепенно закрепляя грамматику, преподаватель несколько расширяет и лексику в основном с помощью учебных текстов, адаптированных текстов художественной литературы, а также аутентичных текстов.

Таким образом, методика преподавания РКИ позволяет интенсифицировать процесс обучения.

В практике преподавания русского как иностранного большое внимание уделяется существованию хороших учебников, в которых методика РКИ излагается в форме последовательно вводимых учебных моделей и упражнений для закрепления грамматических конструкций и активизации лексики, и все они вместе отвечают приведенным выше целевым установкам.

В дополнение к изданным многочисленным учебникам для студентов-иностранцев преподавателями русского языка Международного образовательного центра ЕГУ был издан учебник РКИ - элементарный уровень, в котором методика РКИ адаптирована как для студентов-армян, не владеющих русским языком, так и иностранных граждан, приезжающих в РА. Данный учебник является частью комплекса учебных материалов, предназначенных для обеспечения учебного процесса на двух этапах обучения: элементарном и базовом. Обучение русскому языку по данному учебному комплек- су преследует цели, специфические для каждого из этапов. Так, основной целью элементарного этапа является формирование навыков и умений в области говорения, аудирования, чтения и письма, а также определенного уровня лингвистической и страноведческой компетенции.

В учебнике реализованы ведущие принципы современной методики преподавания русского языка иностранцам: активной коммуникативности, учета национальных особенностей адресата, профессиональной ориентации обучения и т. д. Грамматический материал подается в учебнике на синтаксической основе и организован таким образом, чтобы продемонстрировать его функционирование в речи. Этому же принципу подчинена и подача лексического материала. В связи с этим единицами организации материала выступают речевые образцы, тексты различного жанра и тематики. Речевые образцы представлены различными структурами простого и сложного предложений и отвечают основным требованиям к уровню владения речью, а именно:

1. В области говорения:

а) умение воспроизводить заученные речевье образцы в диалогах;

б) умение использовать речевье образць в ситуации, аналогичной изученной;

2. В области аудирования:

а) умение понять смысл реплик собеседника;

б) умение понять небольшое по объему сообщение;

\section{3. В области чтения:}

умение прочитать и понять содержание текста, построенного на знакомом

лексико-грамматическом материале;

4. В области письма:

умение зафиксировать в письменной форме воспринимаемье на слух фрразы

(диктант).

Учебник прошел апробацию и получил хорошие отзывы специалистов, преподавателей-русистов. 


\section{ЛИТЕРАТУРА}

1. Руденко-Моргун О.И. Русский язык как иностранный: методика и практика преподавания. Вестник ЦМО. МГУ, 1998,N 1.

2. Власова Н.С. Русский язык как иностранный. О методике РКИ, адаптированной для детей русскоязычных эмигрантов из России. М.: МГУ, 2006.

3. Златопольский Ю. Методика преподавания русского как иностранного. Вестник МАПРяЛ, N 22, 1998.

4. Щукин А.Н. Интенсивные методы обучения иностранным языкам. М., 1999.

5. Щүкин А.Н. Методика преподавания РКИ. М., 2003.

6. Лысакова И.П. Русский язык как иностранный. Методика обучения русскому языку. М.: «Владос», 2004

7. Арутюнян В.Н., Бабаханян М.Г., Айвазян Н.С., Балян Г.А. Учебник для студентов начального этапа обучения «Русский язык для начинающих», ЕГУ, 2009.

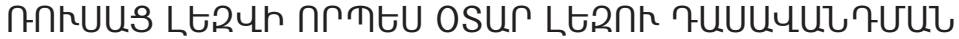

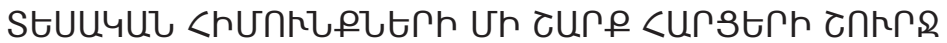

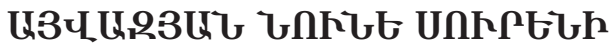

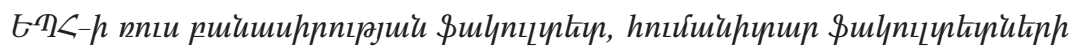

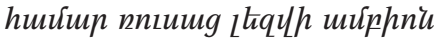

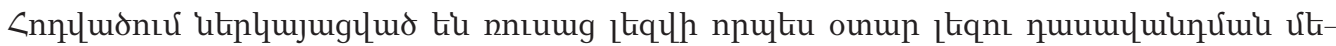

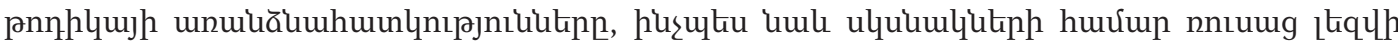

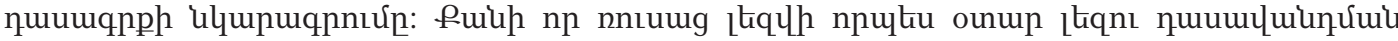

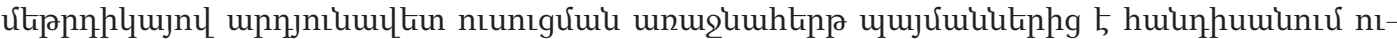

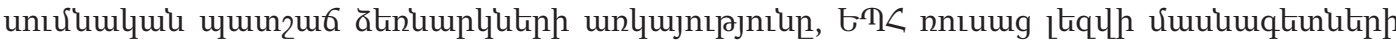

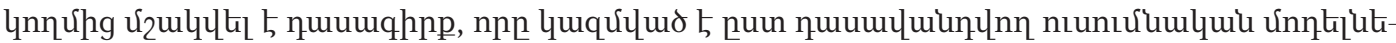

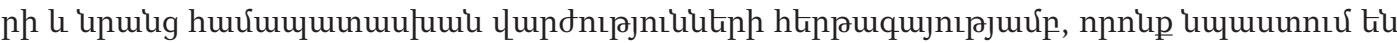

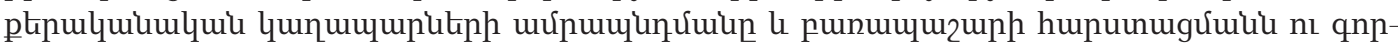
๖nı hhpunưuin:

\section{SOME THEORETICAL ISSUES ON TEACHING RUSSIAN AS A FOREIGN LANGUAGE NUNE AIVAZYAN \\ Faculty of Russian Philology, Chair of Russian Language for Humanitarian Faculties, YSU}

Distinctive features of the methodology of teaching Russian as foreign language, as well as the description of the new textbook of Russian language (elementary level) are outlined in the article. According to the methodology of teaching Russian as a foreign language one of the ways of productive teaching is the usage of good educational materials, a textbook was developed by the Russian language teachers of YSU in which the methodology of teaching Russian as a foreign language is outlined in the form of consequentially given educational models and exercises for fixing the grammatical constructions and for activating the lexis. 